\title{
A patient with seizures, haemoptysis and dyspnoea
}

\author{
M. Meysman*, M. Noppen*, P. Herregodts**, W. Vincken*
}

\section{Case history}

A 27 year old woman was admitted to hospital because of seizures, haemoptysis and dyspnoea. She had been diagnosed as having tuberous sclerosis with mental retardation, epilepsy and secondary hydrocephalia due to a cerebral tuber obstructing the foramen of Monroe. Two years prior to admission, the hydrocephalia of the lateral cerebral ventricles was corrected by a ventriculo-cardial shunt. The patient was a nonsmoker and had no history of asthma. One month before admission, she developed progressively worsening exertional dyspnoea, without coughing. Her medication included carbamazepine, $400 \mathrm{mg}$ daily, and clonazepam, $3 \mathrm{mg}$ daily.

Physical examination showed a patient in moderate respiratory distress. Blood pressure was 130/90 $\mathrm{mmHg}$, pulse rate 120 beats $\cdot \mathrm{min}^{-1}$ and rectal temperature $36.5^{\circ}$ C. Crackles were heard over both lungs. Neurological examination was normal. The patient had nodular lesions on her fingers and facial angiofibroma typical of tuberous sclerosis.

Haemoglobin was $6.7 \mathrm{mmol} \cdot \mathrm{L}^{-1}$ with a mean corpus-

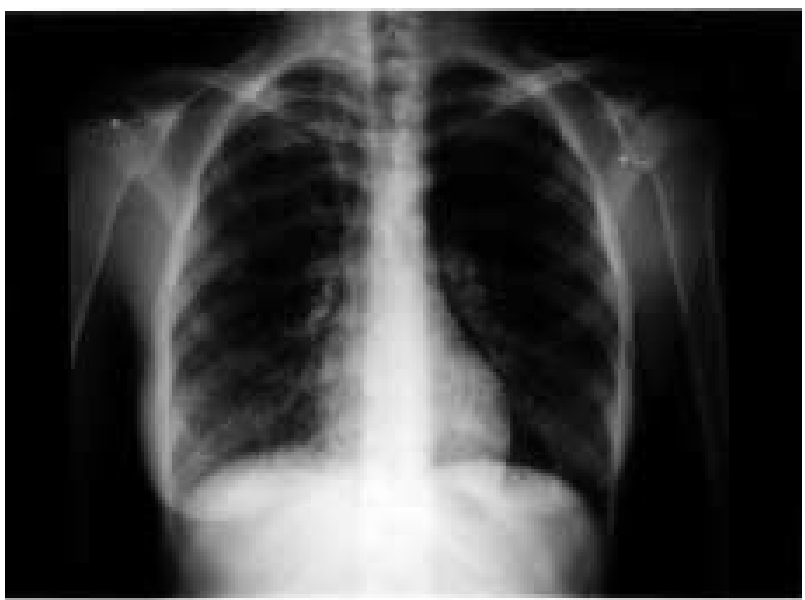

Fig. 1. - Chest roentgenogram. cular volume (MCV) of $79 \mathrm{fL}$. White blood cell count was $5,200 \times 10^{12} \cdot \mathrm{L}^{-1}$, with 0.61 neutrophils, 0.01 basophils, 0.03 eosinophils, 0.11 monocytes and 0.21 lymphocytes. Sedimentation rate was $10 \mathrm{~mm} \cdot \mathrm{h}^{-1}$. Liver and renal function tests were normal. Carbamazepine and clonazepam serum levels were within therapeutic range. Blood, urine and sputum cultures were negative, as was viral and mycoplasmal serology.

Arterial blood gas analysis, whilst breathing room air, showed a $\mathrm{pH}$ of 7.34 , arterial carbon dioxide tension $\left(P \mathrm{a}, \mathrm{CO}_{2}\right)$ of $4.8 \mathrm{kPa}(36 \mathrm{mmHg})$, arterial oxygen tension $\left(\mathrm{Pa}, \mathrm{O}_{2}\right)$ of $9.3 \mathrm{kPa}(70 \mathrm{mmHg})$ with an oxygen saturation of $90 \%$.

Pulmonary function tests showed: forced vital capacity (FVC) $3.0 \mathrm{~L}$ (86\% predicted); forced expiratory volume in one second (FEV1) $1.83 \mathrm{~L}$ (60\% pred), FEV1/FVC $61 \%$; total lung capacity (TLC) $5.02 \mathrm{~L}$ (105\% pred); functional residual capacity (FRC) $2.71 \mathrm{~L}$ (104\% pred); residual volume (RV) $2.02 \mathrm{~L}$ (152\% pred) and transfer factor of the lungs for carbon monoxide $(T \mathrm{~L}, \mathrm{CO}) 3.2$ $\mathrm{mL} \cdot \mathrm{min}^{-1} \cdot \mathrm{mmHg}^{-1}$ (12\% pred).

Bronchoscopy revealed blood in the right bronchial tree, without any active bleeding lesion.

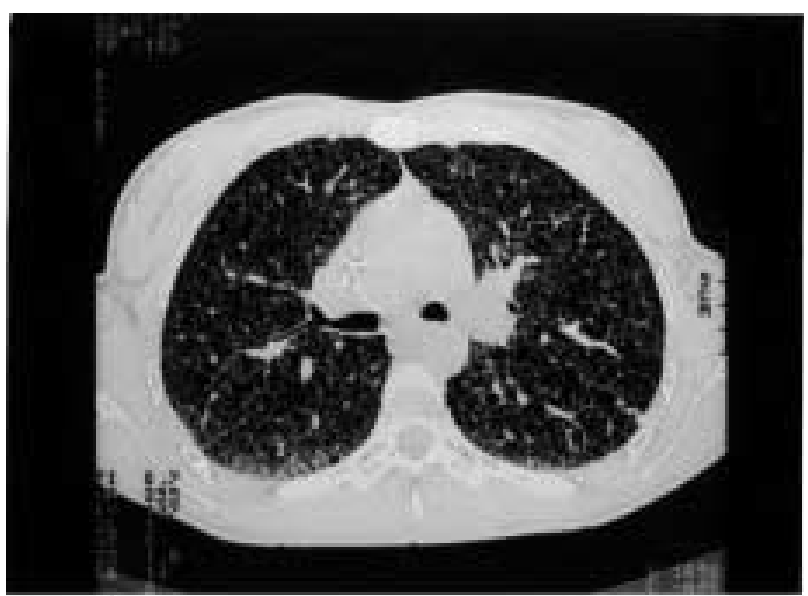

Fig. 2. - Chest computed tomographic scan at the subcarinal level.

*Department of Internal Medicine, Respiratory Division and **Department of Neurosurgery. Academic Hospital University of Brussels, Brussels, Belgium. Correspondence: M. Meysman, Respiratory Division AZ-VUB, Laarbeeklaan 101, 1090 Brussels, Belgium.

\section{BEFORE TURNING THE PAGE; INTERPRET THE FIGURES AND SUGGEST DIAGNOSIS AND TREATMENT.}




\section{Interpretation of roentgenogram and computed tomographic (CT) scan}

The roentgenogram shows a central venous line (the ventriculo-cardial shunt) and a diffuse interstitial pattern (fig. 1). The chest CT scan (fig. 2) reveals widespread, diffuse, small, thin-walled pulmonary cysts, less than 20 $\mathrm{mm}$ in diameter, present in all lung zones.

\section{DIAGNOSIS: "Lymphangioleiomyomatosis in tuber-} ous sclerosis"

The clinical, radiographic and functional findings are consistent with pulmonary manifestations, resembling lymphangioleiomyomatosis in a patient with tuberous sclerosis.

\section{Treatment}

Our patient was treated with $500 \mathrm{mg}$ medroxyprogesterone acetate, intramuscularly once monthly, and there was no further deterioration after 3 months of treatment.

\section{Discussion}

Tuberous sclerosis (Bourneville's disease) is a clinical diagnosis made on the basis of fits, which may be focal or generalized, mental retardation, together with adenoma sebaceum, and shagreen patches and depigmented areas on the limbs and trunk, which characteristically fluoresce under Wood's light [1]. Computed tomography of the brain usually demonstrates calcified and uncalcified subependymal nodules and lesions in the cerebral parenchyma [2].

Pulmonary lymphangioleiomyomatosis (LAM) is caused by proliferation of smooth muscle cells in the walls of small airways, venules and lymphatics of the lung, as well as the mediastinal and retroperitoneal lymphatics [3]. LAMlike lesions occur in fewer than $1 \%$ of patients with tuberous sclerosis. The clinical, radiographic and pathological findings of pulmonary involvement in tuberous sclerosis are indistinguishable from LAM [4]. Some authors consider LAM to be a forme fruste of tuberous sclerosis [5, 6], others believe they are different entities [7].

Almost all patients with LAM are women with childbearing potential [8], although occasionally the disease is reported in post menopausal women [9]. LAM-like lesions in tuberous sclerosis may also occur in males. The typical clinical presentation of LAM includes: spontaneous pneumothorax due to cyst rupture in $40 \%$ of patients; chylothorax due to lymphatic obstruction in $80 \%$ of patients; haemoptysis, resulting from venular obstruction in $40 \%$ of patients; and slowly progressive dyspnoea caused by bronchial narrowing, leading to diffuse pulmonary cyst formation with normal or increased lung volumes and low transfer factor [3, 10].

Typically, the chest roentgenogram shows symmetrically distributed interstial disease. CT scan demonstrates thin-walled cysts, mostly less than $20 \mathrm{~mm}$ in diameter, scattered at random in all parts of the lungs [11]. Ground glass opacities may correspond to pulmonary haemosid- erosis and/or relatively diffuse proliferation of immature smooth muscle cells [12].

The simultaneous findings of cerebral tubers, cutaneous lesions of tuberous sclerosis and the pulmonary manifestations allows the diagnosis of LAM-like lesions to be made without lung biopsy [4].

Although unequivocal data concerning results of ovariectomy, tamoxifen or progesterone treatment are missing, with such treatment clinical and radiological stabilization can be obtained [13]. A reduction of the FEV1/FVC ratio and an increase in \% TLC at the first examination tend to be negative prognostic factors. At lung biopsy, a predominantly cystic type of LAM lesions and higher grades of abnormal areas and cystic lesions showed a tendency to poor prognosis [12].

Keywords: Lymphangioleiomyomatosis, pulmonary cysts, tuberous sclerosis.

\section{References}

1. Roach ES, Smith M, Huttenlocher P, et al. Diagnostic criteria tuberous sclerosis complex. Report of the Diagnostic Criteria Committee of the National Tuberous Sclerosis Association. J Child Neurol 1992; 7: 221-224.

2. Kingsley DPE, Kendall BE, Fitz CR. Tuberous sclerosis: a clinicoradiological evaluation of 110 cases with particular reference to atypical presentation. Neuroradiology 1986; 28: 38-46.

3. Carrington CB, Cugell DW, Gaensler EA, et al. Lymphangioleiomyomatosis: physiologic-pathologic-radiologic correlations. Am Rev Respir Dis 1977; 116: 977-995.

4. Williams DE, Rosenow EC. Exertional dyspnea, hemoptysis and skin lesions in a 34 year old woman. Chest 1993; 104: 587-589.

5. Capron F, Ameille J, Leclerc P, et al. Pulmonary lymphangioleiomyomatosis and Bourneville's tuberous sclerosis with pulmonary involvement: the same disease? Cancer 1983; 52: 851-855.

6. Valensi QJ. Pulmonary lymphangiomyoma, a probable forme fruste of tuberous sclerosis: a case report and a survey of the literature. Am Rev Respir Dis 1973; 108: 1411-1415.

7. Stovin PGI, Lum LC, Flower CDR, et al. The lungs in lymphangiomyomatosis and in tuberous sclerosis. Thorax 1975; 30: 497-509.

8. Taylor JR, Ruy J, Colby TV, Raffin TA. Lymphangioleiomyomatosis: clinical course in 32 patients. $N$ Eng J Med 1990; 323: 1254-1260.

9. Baldi S, Papotti M, Valente ML et al. Pulmonary lymphangioleiomyomatosis in postmenopausal woman: report of two cases and review of the literature. Eur Respir $J$ 1994; 7: 1013-1016.

10. Muller NL, Chiles C, Kullnig P. Pulmonary lymphangioleiomyomatosis: correlation of $\mathrm{CT}$ with radiographic and functional findings. Radiology 1990; 175: 335-339.

11. Lenoir S, Grenier Ph, Brauner MW, et al. Pulmonary lymphangioleiomyomatosis and tuberous sclerosis: comparison of radiographic and thin-section CT findings. Radiology 1990; 175: 329-334.

12. Kitaichi M, Nishimura K, Itah H, Izumi T. Pulmonary lymphangioleiomyomatosis: a report of 46 patients including clinicopathologic study of prognostic factors. Am J Respir Crit Care Med 1995; 151: 527-533.

13. Case Records of the Massachusetts General Hospital (Case 18-1994). N Eng J Med 1994; 330: 1300-1306. 